\title{
Avatares do feminino em Maria Ondina Braga
}

\author{
Avatars du féminin dans Maria Ondina Braga
}

\author{
Maria Araújo da Silva ${ }^{1}$
}

Resumo: Em introdução do livro Mulheres escritoras (1980b), onde reuniu treze admiráveis biografias de mulheres que se impuseram no universo tradicionalmente masculino da escrita, Maria Ondina Braga apresenta um conjunto de escritoras apontadas como exemplo de coragem e tenacidade num universo dominado por preconceitos e pela hipocrisia e intolerância, mulheres que ousaram desafiar os códigos de uma sociedade marcadamente repressora. De igual modo, a vasta produção literária de Maria Ondina Braga apresenta-nos um imenso painel de mulheres habitadas de solidão e de silêncios contidos, ora presas por um cordão umbilical a ritos plurisseculares que the tolhem a liberdade, ora inebriadas pelo sabor excêntrico da transgressão, navegantes solitárias em busca de pistas possíveis no caminho da emancipação.

Palavras-chaves: Maria Ondina Braga; mulher; identidade; alienação; emancipação.

\begin{abstract}
Résumé: En introduction du livre Mulheres escritoras (1980b), réunissant treize admirables biographies de femmes qui se sont imposées dans l'univers traditionnellement masculin de l'écriture, Maria Ondina Braga présente un ensemble d'écrivaines qui figurent comme exemple de courage et de ténacité dans un univers dominé par les préjugés, l'hypocrisie et l'intolérance, des femmes qui ont osé défier les codes d'une société fortement répressive. La vaste production littéraire de Maria Ondina Braga nous offre un vaste panorama de femmes unies par une irréductible solitude et habitées de silences, tantôt intrinsèquement liées à des rites pluriséculaires entravant leur liberté, tantôt attirées par les saveurs enivrantes de la transgression, en quête de lueurs émancipatrices.
\end{abstract}

Mots-clés: Maria Ondina Braga; femme; identité; aliénation; émancipation.

\footnotetext{
${ }^{1}$ Université Paris-Sorbonne - CRIMIC.
} 
Mas, acima de tudo, quero encontrar-me comigo.

(Braga, 1983: 6)

A vasta produção literária de Maria Ondina Braga apresenta-nos um imenso painel de mulheres habitadas de solidão e de silêncios contidos $^{2}$, ora presas por um cordão umbilical a ritos plurisseculares que thes tolhem a liberdade, ora inebriadas pelo sabor excêntrico da transgressão, viajantes solitárias unidas na busca de outros tempos e outras paragens. «Joalheira da vida humana e social», como the chamou um dia Manuel Frias Martins (1983: 169), Maria Ondina Braga mostra-se particularmente atenta aos problemas vivenciados pelas mulheres: «Tenho a obrigação moral de escrever sobre a mulher», afirma numa entrevista concedida em 1983 (Coimbra, 1983: 3). Em introdução do livro Mulheres escritoras (1980b), onde, num ato de solidariedade feminina, reuniu treze admiráveis biografias de mulheres que se impuseram no universo tradicionalmente masculino da escrita (Virginia Woolf, Jane Austen, irmãs Brontë, Colette, Georges Sand, Irene Lisboa, Gabriela Mistral...), a ficcionista escreveu:

Aqui se encontram reunidas figuras femininas muito diferentes, mais corajosas umas que outras, dominadas ou não pelos seus fantasmas, todas, porém, exemplos de força interior, de te-

\footnotetext{
2 Segundo Isabel Pires de Lima, a contenção constitui «o traço primordial das personagens da autora, de modo que parece constituir a própria essência da condição feminina» (1989: 11).
}

nacidade, e defrontando os baixos interesses, os preconceitos, a hipocrisia, a intolerância, as prepotências da sociedade que as rodeava e constrangia. Casos de superior humanidade, ora vitoriosa, ora dilacerada. Minhas companheiras de tantas horas de solidão. A outras companheiras, essas desconhecidas, procurei transmitir, intacta, viva, reconfortante, a sua presença. (1980b)

Na senda das Três Marias³, esta «criadora de almas» - como a própria também se definiu ${ }^{4}$ - não se coibiu de denunciar a miséria, a opressão e a alienação da mulher em páginas de uma sensibilidade erudita que se erguem como um grito no silêncio que aflora numa certa sociedade contemporânea. É interessante observar que as figuras femininas que povoam as suas histórias são geralmente apresentadas por duplicação ou por contraste com uma alteridade interior ou exterior, determinante na afirmação e na construção do $\mathrm{Eu}$ feminino, nutrindo sentimentos de proximidade e identificação ou reforçando a distância onde se espelha o que não são, o que pode-

\footnotetext{
${ }^{3}$ Maria Isabel Barreno, Maria Teresa Horta e Maria Velho da Costa, cuja obra publicada conjuntamente, Novas cartas portuguesas (1972), se insurge contra a ideologia dominante e denuncia diversas formas de violência, nomeadamente a exercida sobre as mulheres, num Portugal fortemente marcado pelo peso da religião e da tradição.

${ }^{4}$ «O professor Vitorino Nemésio costumava dizer que o escritor é um criador de almas e, quanto a mim, é o que tenho feito ou tentado fazer», lembra Maria Ondina Braga numa entrevista com Andreia Menezes (Nova Gente, 1981: 32).
} 
riam ou gostariam de ser 5 . Em busca de uma imagem de si própria, a mulher projeta-se no olhar, nos gestos, nas atitudes de outros seres femininos, diferentes mas irmanados na mesma angústia devastadora. Como sublinha Fernando Mendonça:

As mulheres que centram as narrativas [...] de Maria Ondina Braga são sempre habitadas de solidão, cientes da tristeza que acompanha o amor, bordadoras do silêncio interior quando os olhos e a memória vão ao encontro dos dias, das noites e da morte. (1973: 172-177)

Sonhos, anseios, medos e segredos desenham a cartografia interior que esta «narradora de gentes» (Duarte, 1989: 15) esculpe delicadamente numa obra extensa que reúne poesia, narrativas de viagem, crónicas, contos, novelas e romances. Cruzando a mundividência interior com a dimensão sociológica, as personagens de Maria Ondina Braga inscrevem-se num quotidiano bem palpável onde se jogam as mais diversas tensões e contradições. 0 Minho natal e a sua capital fortemente impregnada de religiosidade, Braga - a cidade onde nasceu e que guarda como marca no seu apelido -, ou os territórios do Oriente onde

\footnotetext{
${ }^{5}$ Segundo Béatrice Didier (1981: 27): «Tantôt l'autre femme sera très proche de l'héroïne, permettant alors l'expression d'un narcissisme fondamental, tantôt, au contraire, très différente, elle permettra, par sa différence même, d'exercer un étrange tropisme, de révéler à l'héroïne ce qu'elle n'est pas, ce qu'elle pourrait être, ce qu'elle aimerait être».
}

viveu largos anos ${ }^{6}$ são os palcos privilegiados de uma vasta produção onde o realismo nunca é escamoteado. Nos textos que têm por pano de fundo a terra natal, a inscrição temporal cristaliza-se através de referências históricas ou de diálogos sobre a vida política e social do país, em que se evidenciam a insatisfação e as desilusões coletivas vividas sob os longos anos do regime salazarista. Neste contexto sociopolítico onde reinam os valores veiculados pela ideologia burguesa dominante, as mulheres sofrem o peso da moral religiosa e da tradição que as tolhe. As noções de bem e de mal veiculadas pela ética cristã despertam nelas fortes sentimentos de culpabilidade, sabendo que os comportamentos transgressivos são punidos com a reclusão e a alienação. $\mathrm{A}$ «enclausurada» definida por Nathalie Heinich (1996) no seu livro sobre a identidade feminina na ficção ocidental surge como figura central nas narrativas de Maria Ondina Braga. A vida monástica, exigente e austera, constitui a única saída para a desilusão amorosa e a expiação dos pecados de

\footnotetext{
${ }^{6}$ Nascida em Braga, deixou a cidade na década de 50 em busca de outros horizontes. Após uma breve passagem pela Escócia, Inglaterra e Paris, rumou até Angola, Goa (onde presenciou a ocupação do território pelas tropas indianas em 1961) e, mais tarde, Macau, onde ensinou português e inglês até 1966, data do seu regresso a Portugal. Volta ao Oriente como leitora de português no Instituto de Línguas Estrangeiras de Pequim em 1982, ano em que redige as crónicas sofridas reunidas em Angústia em Pequim (1984). A convite da Fundação Oriente, regressa a Macau em 1991, tendo fixado memórias desse reencontro na narrativa de viagens Passagem do Cabo (1994).
} 
Eugénia, a protagonista do conto «Estação morta», posteriormente convertida em «irmã Desterro» (Braga, 1980a: 117). O convento, equivalente socialmente instituído da morte, representa também a única saída possível para a jovem Marta do conto «Casa de regeneração», desflorada pelo velho que a empregara (Braga, 1982: 135).

Pertencendo a classes abastadas ou a meios mais desfavorecidos, a mulher-objeto sofre do atavismo familiar e social herdado da tradição: «Mulheres coisas, utilidades ou entretenimentos. [...] As filhas herdavam o fado das mães» (Braga, 1973: 13-14). Em páginas de agudíssima observação, Maria Ondina Braga retrata o microcosmo bracarense que tão bem conhece, descrevendo, por um lado, a pequena burguesia provinciana imersa numa atmosfera angustiante e sufocante, por outro, uma classe popular particularmente ligada às superstições e aos mistérios do mundo rural.

De mãos dadas com a nostalgia do amor, quase sempre inscrito sob o signo da separação e da distância, a tristeza, numa apreciável riqueza de modulações, ocupa o centro desta constelação afetiva que ganha forma num discurso articulado entre transparência e opacidade. Como que empurradas por forças negativas, as personagens ondinianas recuam perante a realização do amor, reduzido a uma parede de vidro e definido em termos de ilusão, de ausência e solidão, como lembra muito justamente Natércia Freire, a propósito da cole- tânea A China fica ao lado: «O Amor - em todas as suas gradações - é um estranho ser que, usando vários rostos, se desloca quase sempre solitário, em espaços indefiníveis» (1968). Pulsões, sofrimentos mudos e frustrações conjugam-se para dizer a derrota ou a morte do amor, simbolicamente ilustrada no romance A personagem: «o idílio entre o marido da Lua e a esposa do Sol; o nascimento da Morte; a Lua e o Sol sozinhos para sempre» (Braga, 1978: 115).

Votada à submissão e ao abandono em meios marcadamente arcaicos e repressivos, as personagens femininas de Maria Ondina Braga carregam a diferença sexual como um fardo que se traduz no "ser» e no «fazer»" ditados pelas conveniências sociais a que todas ficam sujeitas. Em histórias de um quotidiano banal, de vidas comuns mais ou menos esquivas, a mulher é essencialmente captada na sua essência interior, «revelando simultaneamente a profundidade e a complexidade que se escondem debaixo do véu da simplicidade» (Martins, 1983: 170).

Determinado desde o berço, o fatum feminino exprime-se nas práticas quotidianas destas protagonistas subalternizadas e reduzidas ao silêncio num mundo alicerçado pelos pilares do patriarcado. Solitárias e enigmáticas, alimentam-se dos mistérios do amor, da vida e

\footnotetext{
${ }^{7}$ Segundo a terminologia proposta por Philippe Hamon (1977).
} 
da morte. À exceção de «O homem pássaro», os contos reunidos sob o título Estação morta oferecem-nos um magnífico retrato da condição feminina, através de uma vasta galeria de mulheres marginalizadas e irmanadas no mesmo grito de dor e desespero: Carolina, Mariana, Teresa, Ritinha, Dhora, Miss Thérèse, Amélia, Cremilde e a irmã Desterro exprimem o destino comum da mulher cuja vida surge ditada pela vontade masculina: «É a sina das pessoas, a marca com que se nasce», conclui a protagonista do conto «Estação morta» (Braga, 1980a: 18). A submissão, as restrições, as desigualdades, as atitudes autoritárias e os preconceitos machistas são várias vezes evocados num discurso acusatório que vai envolvendo o leitor, espectador de uma trama onde se joga o drama da mulher diminuída por estruturas obsoletas. Refira-se, a título de exemplo, o caso da jovem Marina do conto «As arrecadas», obrigada a despir-se a troco de dinheiro sob o olhar libidinoso de um velho que a assediava: «Põe-te nua; mirava-a e remirava-a; pousava em cima da mesa uma nota de cem mil réis» (Braga, 1980a: 30). Geralmente imersas num universo triste e sombrio, as mulheres de Maria Ondina submetem-se com uma serenidade quase estoica aos códigos da moral burguesa e às normas de decência preconizadas pela instituição do matrimónio, que as atiram para um labirinto sem saída:

Tempo em que a norma do comportamento da mulher casada era nem mais nem menos que a submissão: criar os filhos, servir o marido, aparecer pouco em público a não ser pelo braço do consorte, numa palavra, conformar-se com a sua apagada condição. (Braga, 1998: 30)

Veja-se ainda a vulnerabilidade da mestiça Virgilina, do conto epónimo, consciente da sua condição subalterna e do irremediável abandono a que foi votada:

- Se é verdade que cada um nasce com a sua sina, a minha era servir. Servir as tias, a fidalga, a sogra, o marido...

Duma escrupulosidade doentia, nesse tempo, Virgilina tomava a servidão por bem merecido castigo, e aceitava-a como um instrumento de expiação. Pois não the haviam ensinado que a pureza era a maior das virtudes? Pois não fora criada nos princípios da modéstia cristã? (Braga, 1980a: 95)

À mulher, é-lhe reservado o universo confinado da casa ou o espaço circunscrito e fechado do convento. Em Vidas vencidas, a prima Áurea constitui o exemplo paradigmático da mulher colocada sob o jugo da instância masculina repressiva: «Casada com um sujeito abastado, Áurea nunca mais ninguém a vira, o marido prendendo-a em casa tal se prendesse um pássaro na gaiola. [...] "E já morreu essa prima?" Não. Mas pior que morrer, lá fechada a sete chaves...» (Braga, 1998: 97).

A esfera privada da casa é o reflexo da sociedade onde as relações humanas são regidas pelo respeito das tradições e da religião. 0 
ambiente familiar da jovem Ondina de Vidas vencidas oferece-nos um quadro perfeito de gerações de mulheres inteiramente dedicadas ao lar e às tarefas domésticas. A integridade moral, a simplicidade e o pudor são qualidades evidenciadas pelas personagens femininas que rodeiam a jovem protagonista. Capaz de todos os sacrifícios e de todas as privações, a figura da mãe simboliza a total abnegação e a coragem no feminino neste ambiente familiar inserido num Minho tradicionalista e repressivo, onde tudo é recalcado por pudor e a reserva se impõe na expressão de sentimentos ou gestos de ternura. A dignidade e a austeridade constituem palavras-chave neste universo restrito onde se espelham os valores dominantes da sociedade portuguesa de então.

A opressão social adquire uma maior relevância nas narrativas que se debruçam sobre o universo oriental, onde as idosas de pés enfaixados simbolizam o destino comum de mulheres de alma e corpo doridos, reduzidas ao papel social secularmente atribuído pelo poder patriarcal. Contrastando com o papel de mãe, aureolado de todas as virtudes, o celibato feminino é alvo de marginalização: «Às solteiras, vítimas do engano dos homens ou da sua própria fraqueza, ninguém lhes estende a mão. Por castigo? Nenhuma benevolência, nenhuma compreensão. Que sofram. Que morram» (Braga, 1988: 124).

O tema do exílio domina a coletânea de contos A China fica ao lado, povoado de mulheres mar- ginalizadas e condenadas a um destino com contornos marcadamente trágicos. Basta lembrar a jovem acossada do conto que dá o título ao livro, apresentada como uma vítima silenciosa da dominação masculina ${ }^{8}$, cujo sofrimento incomensurável se resume a uma única frase: «Alheamento era, aliás, a marca da sua vida» (Braga, 1974: 12). As protagonistas dos restantes contos partilham com ela o drama do abandono: A-Mou, a leprosa condenada à exclusão desde tenra idade, miss Carol, a enigmática mulher dos espelhos, ou ainda San $\mathrm{Ku}$, a moribunda de pés estropiados, memória viva de um destino trágico enraizado num arcaísmo intemporal. Numa passagem particularmente reveladora do conto "Os espelhos», Maria Ondina Braga destaca o drama da mulher que todo o convencionalismo amordaça e prende:

\footnotetext{
E, diante das batatas cozidas, dos pires de açúcar, das tigelas fumegantes, sentava-se ao lado de Miss Carol, ao nosso lado (à mesa de toalha de oleado e loiça grosseira), a Tristeza, ou a Pobreza, ou a Solidão, não sei bem. Sei só que era feminina e que incomodava. (Braga, 1974: 27)
}

Através destes singelos lances de vida de mulheres oprimidas e alienadas numa sociedade dominada pelo modelo masculino ocidental e oriental, Maria Ondina Braga tece, em páginas

\footnotetext{
${ }^{8}$ Cf., a este propósito, Pierre Bourdieu (1998).
} 
de denso e apurado sentido estético, um comovente testemunho da sua época. Mas se apresenta, por um lado, a mulher subserviente e amordaçada por estereótipos opressores, não hesita em retratar, por outro, a esperança depositada na igualdade e na emancipação a que o segundo sexo (Beauvoir, 1949) aspira, multiplicando estratégias de rutura que cristalizam um novo tempo tecido de alvoraçada contestação.

Ao povoar a sua ficção de personagens femininas que, impelidas por um desejo de liberdade reprimido durante séculos, procuram escapar à vasta rede de convenções que as tolhe, a escritora subverte os valores dominantes da época, numa clara reivindicação de um estatuto mais digno para a mulher. Nas suas histórias, um instinto de resistência e de revolta incita algumas protagonistas a desafiar a lei do Pai e a assumir o seu próprio destino, animadas pelo gosto do risco e da aventura. Diversas protagonistas não hesitam em romper o casulo, impelidas por uma forte atração pelo diverso', num ambivalente processo de fascínio e estranhamento. São mulheres que assumem o destino masculino, migrantes que se cruzam em terras distantes, em camarotes de navios ou compartimentos de comboios, espaços de encontros e desencontros onde a identidade se confronta com a alteridade. As narrativas tecidas nos territó-

${ }^{9} \mathrm{Na}$ aceção de Victor Segalen (1995). rios africanos e orientais dão-nos um perfeito exemplo de mulheres sem agarras, nómadas solitárias habitadas por uma ânsia de liberdade e de saber. A reflexão da narradora de Estátua de sal sobre a partida, portadora de grande entusiasmo, e a chegada, sinónimo de desencanto, é reveladora do desejo de emancipação que lhes guia os passos. Maria Ondina Braga interpela as suas personagens, exortando-as a contestar a ordem estabelecida. Assim, Clara, a protagonista do conto «Uma jangada na noite», interroga-se sobre a passividade e o consentimento que tomaram conta dela:

\footnotetext{
E tu, e as tuas divagações? Por momentos sente que anda a perder tempo, que devia era correr mundo, conhecer outros usos e maneiras de viver. Experimentar. Experimentar o quê? Sei lá. O amor. Esquecida, esquecida é o que tu estás. Numa terra pacata como a tua, princípios religiosos e tradicionais, escrúpulos, acanhamento, ficaste assim manietada e não te sabes soltar. Liberdade. Muito difícil conquistar a liberdade quando se foi criado na lei da submissão. [...] Ela, todas as noites à borda da rebeldia... em imaginação. (Braga, 1982: 84-85)
}

As narrativas ondinianas são o lugar de reivindicações, de uma lúcida revolta de palavras semeadas ou a germinar, sorrateira, nos espíritos. Amplamente contida, a indignação da narradora de Estátua de sal irrompe no fim do livro: «Eu hirta, arquejante, rebelde. Eu e a minha guerra. [...] Hora da libertação? Eis o derrubar da estante. As minhas "armas" retum- 
bando no sossego da casa» (Braga, 1983:166). Quando não corporizada através de ações e gestos, a ânsia de liberdade adivinha-se nos recantos da alma feminina, como no caso de Noémia do conto «A lição de inglês», que, em plena aula de explicação, desabafa, num clima de intimidade, sobre as tentações que a assolam: «Vou-me divorciar. O Raul não quer. Habituou-se à minha sujeição. Convêm-lhe as aparências, a fachada social de uma muLher legítima, de um lar. Mas o Peter ama-me. $E$, quanto a mim, creio que é a paixão da minha vida» (Braga, 1982: 127).

O mesmo desejo ressoa com toda a força num outro texto com o sugestivo título «A fuga»: «Pôs-se de pé de um salto. Meu Deus, não ia endoidecer agora... agora que estava livre. Sorriu. Livre! De André, dos amigos de André, do materialismo, da eficiência, da utilidade do mundo do André. [...] Livre» (Braga, 1973: 99). A crítica à hipocrisia reinante exprime-se neste conto e em muitos outros onde o espetro machista é claramente denunciado. A dominação masculina é frequentemente contrariada pela revelação de fragilidades que inspiram a piedade de algumas mulheres. A protagonista de «A visita» alimenta sentimentos contraditórios pelo asiático que conheceu, um «animal selvagem» que ora a comove ora a repugna. Para citarmos apenas mais um exemplo, verificamos que, no conto «A fuga», Gabriela vive o dilema da compaixão e do remorso em relação ao marido que engana. Vingança da escrita feminina?, interroga-se, a esse pro- pósito, Béatrice Didier: «Revanche? au miroir du roman féminin, l'homme révélerait surtout sa faiblesse, tandis que la société lui décerne force et pouvoir?» (1981: 30).

A insatisfação e a revolta dominam as três novelas reunidas em Lua de sangue, nomeadamente «O gato», em que o nado-morto representa simbolicamente o mal-estar de Balbina e a sua recusa em dar à luz o filho tão desejado pelo marido. De referir ainda a revolta crescente da jovem chinesa anónima do conto «A China fica ao lado», que, após ter abortado clandestinamente, sai do consultório do Dr. Yu erguendo os braços para o céu como que para simbolizar o triunfo de uma libertação coletiva. Estes temas assumem uma maior relevância no romance $A$ personagem, em que se retrata uma mulher profundamente solitária, dividida entre o desejo e a frustração, símbolo paradigmático de todas as figuras femininas em luta pela emancipação. Paula personifica a mulher culta, inteligente e independente, que consegue impor-se no universo da imprensa, maioritariamente masculino (à exceção de Paula, as mulheres são destinadas a tarefas subalternas no jornal onde trabalha). Indo ao encontro das reivindicações da identidade feminina marcada por anos de descriminação e intolerância, a ousadia da personagem coincide com a transição da ditadura para a democracia. Maria Ondina Braga insiste na inquietação, na dúvida, nas fraquezas e nos sentimentos contraditórios da personagem, levada a usar um duplo especular - a personagem 
ficcional Vânia - para se descobrir. Paula nutre o desejo de sair do esquema imposto pela tradição, personificado pelas mulheres que obedecem à lei do casamento e da maternidade: «Porque me casei? Olhe, porque é o costume, não é?»(Braga, 1978: 58). Ao querer assumir sem entraves as suas aspirações pessoais, a protagonista rompe definitivamente com a vida em que se estiola, simbolizada pela imagem de um peixe no aquário, inerte a boiar à tona da água:

Atento nele: o dia inteiro às voltas no aquário. Os seus olhinhos inexpressivos, neutros, a espreitar-me por trás do vidro grosso. Vem acima, à espera que the dê de comer. Detém-se. (Irá morrer?) Vejo-o inerte a boiar à tona de água. Assusto-me. Não, ainda não morreu. Mergulha. Rebusca entre os seixos. Prossegue no seu rodopio. (Braga, 1978: 28)

Na impossibilidade de alcançar o amor que lhe escapa irremediavelmente e intensifica a sua insatisfação, a protagonista recusa viver com o homem por quem nunca nutriu verdadeiros sentimentos e refugia-se, como tantas outras, numa profunda solidão. Fiel a um ideal pessoal, Paula personifica a mulher emancipada e esperançada no futuro pós-revolucionário, ilustrado numa passagem onde observa simultaneamente um grupo de crianças a brincar na rua e o voo de uma gaivota em pleno céu: «Eu sou outra, de repente, quando desato os cabelos e não respondo ao telefone. Quando fico assim calada a escutar as crianças da rua e a seguir, no ar, o arco abstrato de uma gaivota em liberdade» (Braga, 1978: 50).

Não podemos deixar de estabelecer aqui um paralelo com a paisagem oriental descrita numa cena em que A-Mou, a leprosa do conto «Os lázaros», de rosto marcado pelo estigma do sofrimento feminino e trémula de inquietação e esperança, sobe até ao mais alto do morro, «sonhando com um amanhã novo, diferente, melhor»(Braga, 1974: 73).

À guisa de conclusão, será oportuno afirmar que as protagonistas de Maria Ondina Braga, solitárias e marginalizadas por estruturas obsoletas, personificam uma certa revolta feminina contra uma sociedade obscurantista e atrofiante que as reduz à condição de subalternidade. Navegantes da liberdade em busca de pistas possíveis no caminho da emancipação, estas mulheres assumem um papel ativo, operando, por entre questionamentos identitários e posições discretamente acusadoras, uma progressiva mudança da condição feminina, como salientou Inês Pedrosa:

As mulheres de Maria Ondina Braga não são frustradas, nem passivas, nem convencionais. Que lhes liguem os pés, ao lado da China, que as casem, que as fustiguem, que se esqueçam delas, atrás das portas deste Minho, luas de sangue, tanto faz: elas revertem a opressão, sugam-na, vomitam-na em gatos imaginários, em futilarias, vomitam-na e permanecem (1987: 13). 
Impelida por um forte sentido social e dotada de uma profunda dimensão humana, Maria Ondina Braga borda com a maior simplicidade e sensibilidade a própria vida feminina, propondo um questionamento sobre as relações de poder e os papéis de género, numa escrita que se apresenta como espaço privilegiado de contestação, resistência e luta.

\section{Bibliografia}

Beauvoir, S. (1949). Le deuxième sexe. Gallimard. Paris. Vols. I e II;

Bourdieu, P. (1998). La domination masculine. Seuil. Paris;

Braga, M.O. (1973). Os rostos de Jano. Livraria Bertrand. Amadora;

Braga, M.O. (1974). A China fica ao lado. (2. ${ }^{\text {a ed.). }}$ Livraria Bertrand. Amadora;

Braga, M.O. (1978). A personagem. Livraria Bertrand. Amadora;

Braga, M.O. (1980a). Estação morta. Editorial Vega. Lisboa;

Braga, M.O. (1980b). Mulheres escritoras: Da biografia no texto ao texto da biografia. Livraria Bertrand. Amadora;

Braga, M.O. (1982). O homem da ilha e outros contos. Ática. Lisboa;

Braga, M.O. (1983). Estátua de sal. (3. ${ }^{a}$ ed.). ULmeiro. Lisboa;

Braga, M.O. (1988). Angústia em Pequim. (2. ${ }^{a}$ ed.). Rolim. Lisboa;

Braga, M.O. (1998). Vidas vencidas. Caminho. Lisboa;

Coimbra,A.F. (1983,14 de maio). Ondina Braga: Autobiografia de solidão e liberdade. Correio do Minho, p. 3;

Didier, B. (1981). L'écriture-femme. PUF. Paris;

Duarte, L.F. (1989). A personagem. Letras \& Letras. 20: 15;
Freire, N. (1968, 21 de novembro). Uma breve nota. A China fica ao lado de Maria Ondina Braga. Diário de Notícias;

Hamon, P. (1977). Pour un statut sémiologique du personnage. Em: R. Barthes, W. Kayser, W.C. Booth e Ph. Hamon, Poétique du récit. Seuil. Paris; Heinich, N. (1996). États de femmes. L'identité féminine dans la fiction occidentale. Gallimard. Paris;

Lima, I.P. (1989). Para uma poética da suspensão em Maria Ondina Braga - A casa suspensa uma novela exemplar. Letras \& Letras. 19;

Martins, M.F. (1983). Sombras e transparências da Literatura. Imprensa Nacional-Casa da Moeda. Lisboa;

Mendonça, F. (1973). A Literatura portuguesa no século xx. Hucitec. São Paulo;

Nova Gente (destacável) (1981, 25 de novembro-1 de dezembro), p. 32;

Pedrosa, I. (1987, 5-11 de janeiro). Maria Ondina Braga: Ninguém conta três vezes como ela... Jornal de Letras, p. 13;

Segalen, V. (1995). Essai sur l'exotisme. Fuvres complètes. Robert Laffont. Paris. Vol. 1. 